\title{
Introduction
}

In her song Muhammad My Friend, singer-songwriter Tori Amos toys with the idea that the child whose birth in Bethlehem is described in the Gospels of Matthew and Luke was in fact a girl. The gender of the child is not the only difference between the Jesus of the Gospels and the messiah envisioned by Tori Amos. Whereas the Jesus of the Gospels is crucified naked, alone, and abandoned by his followers, Tori Amos' crucified messiah wears Shiseido luxurybrand lipstick while her friends have gathered by her side to drink tea. ${ }^{1}$

Tori Amos' vision of a girl messiah certainly goes against the grain of the Christian tradition. After all, Luke mentions that the baby Jesus was circumcised. That Jesus was a man has been taken for granted in much of the study. But what kind of a man was Jesus? What did it mean to be a man in the ancient Greco-Roman world? In this study, I seek to answer these questions by examining the ideal masculinities in the Synoptic Gospels.

Interest in the study of masculinities in the Bible emerged in the mid-199os and has since grown slowly but steadily. ${ }^{2}$ Nevertheless, studies on the masculinity of Jesus or masculinities in the Synoptic Gospels are still few and far between. ${ }^{3}$ There remains a need for further study on the masculinity of Jesus

1 Tori Amos, "Muhammad My Friend." Boys for Pele. Atlantic Records, 1996.

2 The first studies of masculinity in the Bible were published around the mid-199os. See, e.g., Eilberg-Schwartz 1994; Moore 1996; 2001; Moxnes 2003. One of the most prolific writers on biblical masculinities has been David J. A. Clines; see Clines 1995; 1998; 2002; 2003; 2007 ; 2010. For other studies on biblical and early Christian masculinities, see, e.g., Aasgaard 2009a; Burrus 2000; Cobb 2008; Creangă (ed.) 2010; Creangă \& Smit (eds.) 2014; Kahl 2000; Kuefler 2001; Larson 2004; Mayordomo Marín 2006; Smit 20o6; Tinklenberg deVega 2006; Young 1994; Zsolnay (ed.) 2017.

3 In his article "Ecce Vir, or: Gendering the Son of Man," David Clines (1998) studies the composite portrait of Jesus of the four canonical Gospels, not the Jesus of any individual Gospel. As such, Clines' study does not pay attention to the differences between the Gospels. New Testament Masculinities, edited by Stephen D. Moore and Janice Capel Anderson (2003), has several articles that concentrate on masculinities in different Gospels. All of the articles concentrate on slightly different points of view and different themes, which makes comparing the Gospels difficult. When studying the masculinity of Jesus in the Gospel of Luke, Brittany Wilson's Unmanly Men: Refigurations of Masculinity in Luke-Acts (2015) focuses only on the passion narrative. Wilson's book also contains relatively little comparison between the Synoptic Gospels. In her monograph Behold the Man:Jesus and Greco-Roman Masculinity (2008), Colleen Conway studies the four canonical Gospels, concentrating on the connection

(C) KONINKLIJKE BRILL NV, LEIDEN, 2018 | DOI 10.1163/9789004361096_002

This is an open access chapter distributed under the terms of the CC BY-NC-NBus.0 license.kainen - 9789004361096 
and ideal masculinities in the Synoptic Gospels. In particular, what we do not yet have is a study that concentrates on both the masculinities of Jesus and the other men in the Synoptic Gospels and compares the masculinity ideals of the Synoptic Gospels. How do the Synoptic Gospels address the same themes and issues concerning masculinity? What are the differences and similarities between the Synoptic Gospels? What are the characteristic features of their respective masculinity ideals?

In this study, I focus especially on the masculinity of Jesus, but I also examine the portrayal of the other male characters, as well as female characters, in the Synoptic Gospels. It is important to study both male and female characters, since masculinity is defined both in relation to femininities and in relation to other masculinities. I do not study the masculinity of the historical Jesus, but concentrate instead on how the Synoptic Gospels portray Jesus and the other characters. According to the two-source theory, Matthew and Luke have used Mark as their source. Do the changes that Matthew and Luke make to Mark's text also reflect a different ideal of masculinity?

There are several definitions of masculinity. In this study, I define masculinity as gender ideology. In other words, masculinity means the ideal a man is supposed to fulfill. The ideal masculinities of the Synoptic Gospels are shown most clearly in the character of Jesus. In the ancient Greco-Roman world, ideal characteristics were masculine; thus, ideal human behavior was generally also masculine to some extent. From the point of view of the early Christians, Jesus was an ideal character, and one may suppose that the Synoptic Gospels sought to portray Jesus as ideally masculine. Therefore, I do not analyze whether the Synoptic Gospels portray Jesus as masculine. Rather, I study what kind of masculinity the Synoptic Gospels present as the ideal. In addition to Jesus' masculinity, I also examine the way in which presentations of other (male) characters reflect the ideal masculinities of the Synoptic Gospels. In order to analyze these ideal masculinities, I compare the Synoptic Gospels with other ancient Greco-Roman texts. What were the ideal masculinities of the Synoptic Gospels and how did they relate to other ideals of masculinity that existed in the ancient Greco-Roman world? As a result of the analysis, I suggest that the Gospel of Luke is the closest to the ancient Greco-Roman ideal of selfcontrolled masculinity. The Gospel of Mark, on the other hand, portrays both Jesus and the disciples as examples of voluntarily marginalized masculinity. Matthew enhances the depiction of Jesus by moving it closer to the ancient

between masculinity and Christology. For each Gospel, Conway chooses themes that shed light on the Christology of that particular Gospel. Again, this makes it difficult to see whether these themes are treated differently in the Gospels. 
Greco-Roman ideal of self-controlled masculinity, but at the same time he maintains that the disciples should voluntarily accept the marginalized position of the early Christians.

In a study like this, there is a danger of seeing everything through gendertinted glasses. Just because Jesus was a man does not mean that everything he did was necessarily gendered. It is important to emphasize that I do not believe that the Gospel writers intended to tell their narratives with a concern for (Jesus') masculinity in mind at all times. On the contrary, gender ideology is not the explicit concern of the writers of the Synoptic Gospels. The Synoptic Gospels do not, for instance, explicitly call Jesus masculine or his opponents unmasculine. Still, we can study the Synoptic Gospels from the point of view of masculinity. Terms such as masculine, feminine, effeminate, manly, or unmanly need not be present in the text in order for the texts to be studied from a gender perspective. ${ }^{4}$ Even without the presence of such terms, knowledge of the ancient ideals of masculinity may illuminate the text. ${ }^{5}$ For example, the changes that Matthew and Luke made to Mark's text may have shaped the portrayal of the ideal masculinity of the Gospels, even if the effect of these changes on the ideal masculinity was not intentional.

\section{Of Masculinities and Men}

In order to study masculinity in the Synoptic Gospels, we must begin by defining the term 'masculinity'. What are we talking about when we talk about masculinity? It has become popular since the 1970s to differentiate between biological

4 See Mari Matsuda's (1990-1991, 1188-1190) method of "asking the other question": "When I see something that looks racist, I ask, 'Where is the patriarchy in this?' When I see something that looks sexist, I ask, 'Where is the heterosexism in this?' When I see something that looks homophobic, I ask, 'Where are the class interests in this?" Thus, even if gender or masculinity is not the explicit topic in the narrative, one can "ask the other question" of where gender or masculinity can be found in the text.

5 See Parsons (2006, 67), who studies physiognomy in Luke-Acts and notes: "As we search for evidence of ancient physiognomy in the Lukan writings, we will do well to make a crucial distinction between topics on which Luke touches and subjects about which Luke teaches. That is to say, in certain passages of Luke and Acts, knowledge of ancient physiognomic convention will shed additional light on the text. But that does not mean that these conventions represent what Luke thinks about the subject." Emphasis original. In the same way, knowledge of the ancient ideals of masculinity sheds additional light on the Synoptic Gospels even if masculinity was not the explicit concern of the writers. 
sex ('male,' 'female') and socially constructed gender ('man,' 'woman'). ${ }^{6}$ In recent years, it has become increasingly common to perceive that biological sex is as much of a social construct as gender. ${ }^{7}$ Nevertheless, I still find the distinction between sex and gender useful. ${ }^{8}$ People who are biologically male are not necessarily considered manly or masculine. Instead, some males are labeled as effeminate. In everyday language, the terms 'masculinity' and 'femininity' are not used to describe the sex difference between males and females, but to express the ways in which men differ among themselves and women differ among themselves. ${ }^{9}$ Because masculinity is not a quality that all males have, I differentiate between maleness and masculinity. ${ }^{10}$ Maleness is the result of the biological make-up of males (e.g., chromosomes and hormones). Maleness is biological, whereas masculinity belongs to the realm of gender. ${ }^{11}$ As will be shown in Chapter 2, masculinity was not considered an inherent quality of all males in the ancient Greco-Roman world either.

In masculinity studies, masculinity is usually defined either as an identity or as an ideology. ${ }^{12}$ Since the object of my study is not how the historical Jesus identified himself as masculine but rather the text of the Synoptic Gospels and the ideals presented there, in this study masculinity refers to gender ideology. In other words, masculinity means the ideal that a group has: what the ideal

6 E.g., Rubin 1975, 179: "Gender is a socially imposed division of the sexes. It is a product of the social relations of sexuality." These social relations "transform males and females into 'men' and 'women."

Kessler \& McKenna's influential book Gender: An Ethnomethodological Approach (1978) can be seen as the originator of this development. See also Fausto-Sterling 1993; 2000; Herdt 1994, 78.

8 See Bjelland Kartzow (2010, 383-385), who suggests that in antiquity slaves and free persons had their biological sex in common, but belonged to different gender systems. Connell 2005, 69. It is also possible for a woman to be considered masculine. On female masculinity, see Halberstam 1998.

10 Flanigan-Saint-Aubin (1994, 255 n. 3) makes a similar distinction between the "sense of maleness," which is biological and a result of hormonal forces, and "masculinity or masculine identity" (manliness), which is a social process and result of the attitudes and actions of the culture.

11 Whitehead and Barrett $(2001,16)$, for example, note that "although no human behaviour is totally uninfluenced by biology, masculinity reflects social and cultural expectations of male behaviour rather than biology." The relationship between biological sex and socially constructed gender is complex, and an in-depth scientific analysis of the matter goes beyond the scope of my study. 
man is like, or how a man should behave. ${ }^{13}$ It must be stressed that gender ideology does not necessarily reflect the reality of men. All men do not fulfill the ideal and are not considered masculine. For a man to be considered masculine, his masculinity must be approved by other men. This means that men often have to negotiate their masculinity with other men. Another important thing to note is that the ideals of how a man is supposed to behave are not universal, but differ from society to society. ${ }^{14}$ Every culture also has several different ideologies of masculinity instead of one dominant masculinity ideology. ${ }^{15}$ Gender ideologies, like all ideologies, are not normative: not all people share them. This means that it is possible for each group of people to have their own gender ideology or ideal masculinity. As we will see in Chapter 2, this was also the case in antiquity. There were several competing ideals of masculinity in the ancient Greco-Roman world.

Recent studies on masculinity have acknowledged the multiplicity of masculinities. Thus, it has become common to speak of "masculinities" in the plural. These different masculinities are not equal, but form a network of power relations. Therefore, I take as a starting point Raewyn Connell's differentiation between hegemonic and non-hegemonic masculinities. ${ }^{16}$

13 I define 'ideology' as a set of ideals and values that a group has. My definition of masculinity is thus close to that of Craig Williams (1999, 4): "Masculinity refers to a complex of values and ideals that can more profitably be understood as a cultural tradition than as a biological given: the concept refers to what it is to be fully gendered as 'a man' as opposed to merely having the physical features held to signify 'a male." Cf. Oxford English Dictionary, which gives as one of the definitions for ideology "a set of beliefs governing conduct." For definitions of ideology, see Eagleton 1991, 1-6.

14 Ethnographic studies of primitive societies have shown that the ideals of masculinity differ considerably from one society to the next, from the aggressive Mundurucú in Brazil and Amhara in Africa to the non-violent and gentle Machiguenga in Peru and Tahitians. Coltrane 1992, 87-89. See also Gilmore 1990.

15 In their study on class relations, Abercrombie and Turner argue that there is no one dominant ideology that is then adopted by the subordinate classes. On the contrary, the subordinate classes rarely share the ideology of the dominant class. This was especially the case earlier in history, when there was no mass media to help distribute the ideology of the dominant group. Abercrombie and Turner argue that the ideology of the dominant class has historically had more significance for the internal cohesion of the dominant class itself. Abercrombie \& Turner 1978, 149-163.

16 This division is originally found in Tim Carrigan, R. W. Connell, and John Lee's article "Toward a New Sociology of Masculinity." Carrigan, Connell \& Lee 1985. The concepts of hegemonic and non-hegemonic masculinities have been expanded in Connell's later studies. Connell 1987, 183-186; 2005, 76-81; 1991; see also Connell 1993; 1995; 1997; 1998; $2000 ; 2002$. 
Hegemonic masculinity is the masculinity of the hegemonic or dominant group. Connell maintains that gender is always a relational concept and thus hegemonic masculinity is also constructed in relation to femininities and other masculinities. ${ }^{17}$ According to Connell, hegemony means "a social ascendancy achieved in a play of social forces that extends beyond contests of brute power into the organization of private life and cultural process." ${ }^{18}$ Moreover, hegemony does not mean total cultural dominance-there are also other masculinities.

It is important to note that hegemonic masculinity is not a fixed character type. There is no set of characteristics which is always and everywhere in the hegemonic position. Instead, hegemonic masculinity is the masculinity that occupies the dominant position in a certain configuration of gender relations. Connell emphasizes that hegemony is a currently accepted strategy, which means that its position is always contestable. Hegemony, then, can be disrupted or can disrupt itself. Thus, in certain situations new groups may challenge the old hegemony and construct a new hegemony. This means that historical change of masculinities is possible. Connell notes that in modern Western society, masculinity is heterosexual, aggressive, competitive, and homosocial. It emphasizes hierarchy and the capacity to dominate. ${ }^{19}$ What was the ancient Greco-Roman hegemonic masculinity like? The majority of ancient GrecoRoman texts were most likely written by members of the elite. They thus formed the source for hegemonic masculinity in the ancient Greco-Roman world. In Chapter 2, I examine in more detail the hegemonic masculinity of the ancient Greco-Roman world.

Hegemonic masculinity is more of an ideal, since most men cannot actually meet its standards. Nonetheless, hegemonic masculinity gives a position of power to men, meaning that the majority of men have certain advantages over women and children. This also means that since most men benefit from hegemonic masculinity, they do not oppose it. Connell calls this complicit masculinity. ${ }^{20}$ It could be characterized as a tacit agreement with the hegemony. Connell suspects that in the contemporary world, men who are

17 Connell 2005, 44.

18 Connell $1987,184$.

19 Connell 1997, 8. For example, the hegemonic masculinity of the late 2oth-century USA could be expressed in the words of Erving Goffman: "In an important sense there is only one complete unblushing male in America: a young, married, white, urban, northern, heterosexual, Protestant father of college education, fully employed, of good complexion, weight, height, and a recent record in sports." Quoted by Pleck 1995, 13. 
complicit with hegemonic masculinity form the largest group of men, ${ }^{21}$ but we cannot presume that this is the case in every culture.

Since hegemonic masculinity is constructed in relation to other masculinities, there are also relations of dominance and subordination between groups of men. Subordinated masculinities are associated with femininity. Femininity is defined by the hegemonic masculinity as whatever masculinity is not, and therefore the subordinated masculinities are portrayed as stereotypically effeminate. For example, since contemporary hegemonic masculinity emphasizes heterosexuality, the most common form of contemporary subordinated masculinity is homosexual masculinity. ${ }^{22}$ There are also other types of subordinated masculinities. Connell points out that some heterosexual men are "expelled from the circle of legitimacy" because they do not fulfill the requirements of the hegemonic masculinity in certain ways. These men are also feminized by the hegemonic masculinity and called, for example, wimps or sissies. ${ }^{23}$ Connell also emphasizes that these other masculinities are not necessarily clearly defined. On the contrary, they might even be denied recognition as alternative masculinities. ${ }^{24}$ In the ancient Greco-Roman world, effeminate men were called xivalool or cinaedi. Eunuchs were another group of men considered to be effeminate in antiquity. Unlike in the contemporary world, however, sexual behavior was only one facet that led to men being labeled as effeminate. As we will see in more detail in Chapter 2, in the ancient Greco-Roman world effeminacy was caused by a lack of self-control.

Hegemony, complicity, and subordination are relations internal to the gender order. However, gender is not independent of other social structures like class, race, or ethnicity (or religion, which Connell does not mention). Gender intersects these other structures, creating further relationships between masculinities. ${ }^{25}$ Connell calls masculinities that intersect with other structures marginalized masculinities. If the contemporary hegemonic masculinity is embodied by a white, middle-class man, then a black, middle-class man is marginalized because he is black, whereas a poor, black man is doubly marginalized because he is poor and black. Marginal religious groups like Jews in diaspora or the early Christians would also have had a marginal masculinity. According

\footnotetext{
21 Connell 1997, 8.

22 This does not mean that homosexuality is always necessarily subordinated in every culture. For example, same-sex sexual behavior is ritualized in some cultures.

23 Connell 2005, 79.

24 Connell $1987,186$.

25 On intersectionality, see, e.g., Matsuda 1990-1991; Nash 2008; Davis 2008; Bjelland Kartzow 2010.
} 
to Connell, some aspects of marginalized masculinities may be authorized by the hegemonic masculinity. For instance, a black athlete may be seen as an exemplar of hegemonic masculinity. However, this does not grant authority to other black men. ${ }^{26}$ In the ancient Greco-Roman world, gladiators can be seen as an example of a marginalized masculinity authorized by the hegemony. ${ }^{27}$

In sum, one of the most important features of a hegemonic masculinity is the power to state who is and who is not really masculine or to ignore certain masculinities. Subordinated masculinities are the necessary "other" against which the hegemonic masculinity mirrors itself. They are labeled as effeminate. Marginalized masculinities, on the other hand, are not necessarily feminized but pushed out, ignored, or denied existence. They can nevertheless be considered examples of masculinity; in other words, their masculinity can be "authorized" in some ways.

\section{A Reassessment of Connell's Theory}

The strength of Connell's theory is that it acknowledges the diversity of masculinities and the intersectionality between gender and other social structures. It also takes into account the possibility of historical change: if the current hegemonic masculinity does not answer the demands of the situation, another ideal of masculinity may take its place and become hegemonic instead. ${ }^{28}$ Because of this, Connell's categorization is widely used in masculinity studies. Nevertheless, it has also been evaluated critically. ${ }^{29}$

Some of the criticism stems from the subsequent usage of the term "hegemonic masculinity." Connell emphasizes the relational nature of gender. Hegemonic masculinity exists only in relation to other masculinities. However, scholars have often used the concept of hegemonic masculinity attributionally as a list of qualities or traits. This makes hegemonic masculinity a static and fixed structure. It also loses sight of the competition and contest between different masculinities. Connell maintains that gender is a set of power relations, but critics note that in subsequent studies scholars have used power as

26 Connell 2005, 81.

27 See further in Chapter 2.

28 See also Wetherell \& Edley 1999, 336.

29 Connell answers the criticisms against his theory in Connell \& Messerschmidt 2005. 
an attribute of hegemonic masculinity rather than as a social relationship between individuals. ${ }^{30}$

Despite these criticisms, I still maintain that Connell's theory offers the best starting point for the study of masculinities. The critics do not question the existence of hegemonic and non-hegemonic forms of masculinity, but suggest that Connell's formulation of hegemonic masculinity should be further developed. ${ }^{31}$ Connell emphasizes that the relationships between hegemonic and non-hegemonic masculinities provide a sparse framework. ${ }^{32}$ I suggest that Connell's framework can be developed to better illustrate the complex relationships between different masculinities.

Margaret Wetherell and Nigel Edley maintain that Connell's framework is too simplistic to accurately portray the complexity of the real world. They question, for example, whether there is only one hegemonic masculinity at any given time, and they call for a more complex account of hegemonic masculinity than the current one. ${ }^{33}$ Following Wetherell and Edley, I do not think that there is necessarily just one hegemonic masculinity. On the contrary, there may be several masculinities competing for the hegemonic position. For example, in the ancient Greco-Roman world there were several ideals of how a man was supposed to behave. As we will see in Chapter 2, some writers emphasized the importance of control over others, while others maintained that a man should first and foremost control himself. Both of these masculinity ideals could be seen as competing for the hegemonic position. It is important to note that

30 Hearn 2004, 58; Jefferson 2002, 70-71; Lusher 2008, 42; Martin 1998, 473; Whitehead 2002, 93-94. See also Demetriou 2001. According to Petersen (2003), in later studies that apply Connell's theory the connection between masculinities and power has disappeared, and the term "masculinities" is used simply to depict the diversity or plurality of masculinity. Connell (2000) accepts this criticism but argues that "the broader critique of masculinity research for assuming fixed identities, or stability in masculinity, is not accurate. Research on the social construction of masculinities has placed a good deal of emphasis on the uncertainties, difficulties, and contradictions of the process."

31 Lusher $(2008,40)$ also notes that the critiques of Connell do not undermine the plurality and hierarchy of masculinities, but rather "seek to elaborate and expand the details."

Connell 2005, 81. The terms are also "not fixed character types but configurations of practice generated in particular situations in a changing structure of relationships." Connell's notion of masculinity as "a configuration of practice" places the emphasis on actual behavior. Masculinities come into existence as people act; they do not exist prior to social behavior as identities or personalities. Connell 1995, 46; 2000. Connell's "configuration of practice" is slightly different than Butler's theory of gender as performance. See Butler 1990; 1993; see also West \& Zimmerman 1987. Connell explains the distinction in Ouzgane \& Coleman 1998.

Wetherell \& Edley 1999, 337, 351-352. See also Jefferson 2002, 71. 
masculinities are not lists of traits or attributes. The masculinities competing for the hegemonic position can have completely different ideals.

Connell calls masculinities that intersect with other structures marginalized masculinities. Connell mentions class, race, and ethnicity as examples of these intersections. However, there is no reason why sexuality, body type, or temperament could not be counted among these intersections. This means that the two groups Connell mentions as examples of modern subordinated masculinities - gays and "sissies" (feminine-looking men or men with gentler temperament) — could also be categorized as marginalized masculinities.

Rather than differentiating between marginalized and subordinated masculinities, it might thus be better to see subordinated masculinities as part of marginalized masculinities. The majority of marginalized masculinities remain pushed out, ignored, or denied existence - and, as such, they are culturally invisible. However, not all marginalized masculinities have the same status. Marginalized masculinities can also be given positive evaluation by the hegemony. In other words, they can be authorized by the hegemony and gain cultural visibility. Marginalized masculinity may also gain negative evaluation by the hegemonic masculinity. They may be labeled effeminate and thus (in Connell's terms) become subordinated by the hegemony. Subordinated masculinity is culturally visible as the "other," an example of what the hegemonically masculine man should not be like.

Stereotyping a masculinity as effeminate can be used as a way of marginalizing a masculinity. For example, Jewish men in diaspora have historically been both marginalized and feminized. ${ }^{34}$ Labeling a group of people as effeminate can happen also between groups competing for the hegemonic position. In the ancient Greco-Roman world, writers called tyrants effeminate, which was an effective strategy for denying the legitimacy of their power and marginalizing them as not real men.

On the other hand, some type of masculinity within non-hegemonic masculinities can be in a more dominant position in relation to others, despite not being in the hegemonic position in the culture overall. For example, in the Greco-Roman world eunuchs were generally considered effeminate. Thus, their masculinity was subordinated. Nevertheless, not all eunuchs had the same social status. Some eunuchs gained political power, which made them more "authorized" than other eunuchs. For instance, the Ethiopian eunuch in Acts 8:26-40 appears to be more authorized than the self-castrated eunuchs of Matthew 19:12. In a similar manner, slaves were marginalized but the

34 See, e.g., Kimmel 1988, 153-154; Boyarin 1997; Brod 1994, 92. Kimmel $(1988,153)$ notes that the "Middle-Eastern machismo" is very different from Jewish culture in the diaspora. 
masculinity of gladiators (most of whom were slaves) could be seen as authorized by the hegemony. ${ }^{35}$

It is important to emphasize that authorization and subordination are both strategies used by hegemonic masculinities, which authorize and subordinate other masculinities. The amount of marginalization, as well as the amount of authorization and subordination, varies. In addition, different hegemonic masculinities may evaluate different marginalized masculinities in various ways.

The majority of masculinity studies, both outside of and in the field of biblical studies, have taken as their starting point the privileged position of hegemonic masculinities. Non-hegemonic masculinities are not studied as much and their relation to hegemonic masculinities remains undertheorized. ${ }^{36}$ As mentioned above, Connell acknowledges that some aspects of marginalized masculinities may be authorized by the hegemonic masculinity. Nevertheless, Connell studies masculinities mostly from the point of view of the hegemonic masculinity. For this reason, Connell's framework has also been criticized for lacking in-depth theorization of subordinated and marginalized masculinities. For instance, Tim Edwards notes that although Connell mentions race as an important aspect of marginalized masculinity, race per se gets either no or only cursory attention. ${ }^{37}$

In her monograph Behold the Man: Jesus and Greco-Roman Masculinity, Colleen Conway takes as the starting point of her study the hegemonic masculinity of the ancient Greco-Roman world. Conway examines how New Testament texts relate to the hegemonic masculinity of the Greco-Roman world. The hegemonic ideology was held by the elite, but according to Conway it was also supported by the lower classes, including Christians. ${ }^{38}$ However,

35 See more on this in Chapter 2.

36 This is also noted by Beasley 2005, 196, 213-216. However, although marginalized masculinities remain undertheorized, this does not mean that marginalized masculinities have not been studied at all. There are studies on contemporary marginalized masculinities of, for example, Jewish, African-American, and Mexican immigrant men. See, e.g., Abreu et al. 2000; Baca Zinn 1989; Bell 1995; Bucholtz 1999; Espiritu 2007; Franklin 1987; Harper 2007; Hondagneu-Sotelo 1992; Hondagneu-Sotelo \& Messner 1994; hooks 1995; 2004; Hunter \& Davis 1992; Lazur \& Majors 1995; Majors 1989; 2001; Rogers 2008; Staples 1989.

37 Edwards 2006, 75. Chaney (2009) criticizes Connell for ignoring race and ethnicity, but her criticism is misdirected since she does not seem to be aware of Connell's concept of marginal masculinities.

38 Conway 2008, 10. 
one can question whether most men in the ancient Greco-Roman world were indeed complicit with the hegemonic masculinity. ${ }^{39}$

Conway notes that there were several opinions about what was masculine in the ancient Greco-Roman world. For example, she argues that there were different attitudes toward anger, which were in tension with each other. Conway maintains that all of these different attitudes were part of the hegemonic masculinity and that the hegemonic masculinity was internally contradictory. ${ }^{40}$ One might wonder, however, if the hegemonic masculinity was so multiform and contradictory, can it really be called one ideal? ${ }^{41}$ Although it is possible for a person to hold contradictory ideals, this does not make the ideal itself contradictory. If all of the ideals present in ancient Greco-Roman texts are seen as part of the same hegemonic ideal, it is possible to label almost any behavior as hegemonically masculine, to the point that the term loses its meaning. As argued above, it is better to see these different ideals as part of several masculinities that were competing for the hegemonic position.

The hegemonic ideals reflect the ideology of only a minority. According to Connell, even though only a minority of men can truly embody hegemonic masculinity, the majority of men are complicit with this hegemonic ideal. ${ }^{42}$ However, this might not have been the case in antiquity, where there were no mass media to help spread the gender ideologies of the elite. It is impossible to know how widely the concerns of the elite writers were shared by the members of the lower classes. ${ }^{43}$ Furthermore, even if non-elite people were aware of the hegemonic ideals, it does not mean that they shared these ideals. ${ }^{44}$

In the first century $\mathrm{CE}$, Christianity was not in a hegemonic or culturally dominant position, so it could not represent the hegemonic masculinity in the Greco-Roman world. On the contrary, early Christianity was a marginalized group. Marginalization does not necessarily mean active persecution here; it could simply be that the dominant groups were ignoring or not even aware of the existence of the early Christians. The fact that there are so few mentions of Christians in the Greco-Roman literature of the first and second centuries CE

39 See Gleason $\left(2003,325^{-327}\right)$, who remarks that scholars should consider whether the ideal masculinity of the elite really represented the ideals of ordinary people.

$40 \quad$ Conway 2008, 25-29. See more on emotions and masculinity in Chapter 6.

41 A similar question is raised by Sipilä $(1994,28)$ regarding the concept of hegemonic masculinity in general.

42 Connell 2005, 79.

43 Kuefler 2001, 8.

44 Thatcher $(2009,34)$ notes that the "powerful people are never fully able to impose their version of reality on subordinate classes." See also Scott 1990; Abercrombie \& Turner 1978. 
attests to the marginality of early Christianity. ${ }^{45}$ Early Christian men were not labeled as effeminate in the ancient Greco-Roman texts, so their masculinity was not subordinated. The cultural invisibility of the early Christians of the first century CE made their masculinity marginalized. ${ }^{46}$

\section{Theorizing Marginalized Masculinities}

Changing the focus from hegemonic to marginalized masculinities can offer a corrective to the overemphasis of hegemonic masculinities. ${ }^{47}$ Marginalized masculinities are defined from the point of view of the hegemonic masculinities. This tells us nothing about how the marginalized masculinities view the hegemonic masculinity or whether they accept the evaluation of the hegemonic group. Neither does it tell us anything about what strategies marginalized masculinities employ in relation to hegemonic masculinities. I propose that this is where complicit masculinity comes into the picture.

45 The first mentions of Christians by non-Christian writers are from the second century. Of these, Tacitus (Ann. 15.44), Suetonius (Nero 16), and Pliny the Younger (Ep. 10.96) portray early Christianity negatively, whereas Epictetus (Diatr. 2.9.19-21, 4.7.6), Marcus Aurelius (Med.11.3), and Lucian (Peregr. 11-13; Alex. 25, 38) are more neutral. See Huttunen 2013. The rarity of the mentions of Christians in the ancient Greco-Roman texts of the first century CE attests to the cultural invisibility of early Christianity. In addition, in the first century CE, Christianity was a minority group. Stark $(1997,4-7)$ calculates that there were approximately 7,530 Christians in the year $100 \mathrm{CE}(0.0126 \%$ of the population of the entire Roman Empire). Even if this number is on the low side, it shows that in the first century, early Christianity was small. The majority of early Christians were not members of the elite. For the social status of the early Christians of the first century, see Stegemann \& Stegemann 1999, 227-232, 288-316.

46 Christianity only gained the hegemonic position after the Constantinian shift. Mathew Kuefler (2001) has studied how the Christian masculinity gained the status of hegemonic masculinity from the third to fifth centuries CE. Kuefler argues that the previous hegemonic masculinity, which emphasized the political and military power of the Roman men, could not respond to the needs of the elite. The imperial succession excluded Roman men from the position of political power while at the same time the military power of Rome was declining. According to Kuefler, the ideal masculinity of Christianity offered a better answer to the changing situation than the traditional ideals of masculinity. Kuefler suggests that the ideology of Christian masculinity was one possible reason why Roman men converted to Christianity.

Hondagneu-Sotelo and Messner (1994, 214) have argued that the standpoint of the oppressed groups should be taken as the point of departure in masculinity studies. 
Connell talks about complicit masculinity in the singular, but it is also possible for several masculinities to be complicit in different ways, with some perhaps being more complicit and others less complicit. I suggest that it might be better to see complicit masculinity not as a type of masculinity, but rather to understand complicity as one of the strategies that a masculinity can adopt in relation to hegemonic masculinities. ${ }^{48}$ In other words, complicity means closeness to the hegemonic masculinities. Different marginalized masculinities can be complicit with the hegemonic masculinities to varying degrees. Marginalized masculinities can still be complicit with the hegemony-in other words, they can be in agreement with some of its ideals. ${ }^{49}$ The closer the masculinity is to the hegemonic masculinities and the more ideals a marginalized masculinity shares with a hegemonic masculinity, the more complicit that masculinity is. Authorization of a marginalized masculinity can be seen as complicity accepted by the hegemony, but complicity may also not be accepted by the hegemonic masculinities.

Being complicit with the hegemonic masculinities (or just one hegemonic masculinity or some aspects of that hegemonic masculinity) is not the only strategy a marginalized masculinity can adopt. Marginalized masculinities may also be non-complicit and in opposition to the hegemonic masculinities, or they may accept their marginalized status voluntarily. For example, contemporary marginalized masculinities seem to have different strategies for negotiating relationships with hegemony. Some of these strategies may be more complicit, whereas others are in opposition to hegemony. For instance, hypermasculinity is a common strategy among African-American and Latino cultures. ${ }^{50}$ Hypermasculinity can be defined as an overemphasis of the aspects of power and control that are important for the contemporary hegemonic masculinity. Maxine Baca Zinn suggests that hypermasculinity is an attempt to

48 See Wetherell and Edley $\left(1999,340-35^{2}\right)$, who maintain that complicity and resistance should be used as labels for discursive strategies rather than for types of men. Wetherell and Edley note that there are several ways in which men relate to hegemonic masculinity, ranging from resistance to complicity. They conclude their study by suggesting that there are three positions: 1) the heroic position exemplifies Connell's complicit masculinity; 2) the "ordinary" position sees self as moderate or average and the heroic masculinity as over the top or extreme; and 3) the rebelling position sees self as unconventional and resistant to the hegemonic masculinity. The relationship between these resistant and complicit practices is not a simple dichotomy. Rather, the production of gendered self is a complex process. It is possible for complicity and resistance to be mixed together.

49 Connell (1991) mentions in passing that it is possible for marginalized men to be complicit with hegemonic masculinity, but Connell does not theorize about this further.

See, e.g., Lazur \& Majors 1995; Majors 1989. 
gain control in a situation where the men of marginalized groups do not have access to socially valued roles. ${ }^{51}$ Harry Brod maintains that two strategies can be found in modern Jewish masculinities, namely, conforming to dominant norms and cross-gender alliances. ${ }^{52}$

Within cross-cultural studies, it has been suggested that acculturating, nondominant groups have several ways of relating to the dominant culture. ${ }^{53}$ For example, J. W. Berry has studied the different ways that acculturating groups can relate to the dominant culture. ${ }^{54}$ First, Berry asks whether it is a value for the acculturating group to maintain the cultural identity and characteristics of one's own group. Needless to say, in the early Christian texts maintaining cultural identity as a Christian is a value. The New Testament texts are more interested in the question of how Christians are supposed to relate to the surrounding Greco-Roman society. ${ }^{55}$ The second question Berry asks is whether it is a value to maintain relationships and participate with other groups. If a person wants to maintain relationships with other groups, Berry calls the chosen strategy integration. If the person wants to maintain their cultural identity but avoids interaction with other groups, Berry calls it separation. ${ }^{56}$

This is a modern theory and one should be cautious in applying it to antiquity. However, Berry's categorization is helpful in showing that marginal groups can have different attitudes of acceptance and resistance toward the dominant culture. Berry's theory illustrates that marginal groups may approve certain facets of the dominant culture. This is similar to Connell's concept of complicity. Thus, some of the early Christian masculinities might have been complicit

$51 \quad$ Baca Zinn 1989, 94. See also Torres 2007, 34.

$52 \quad$ Brod 1994, 92. On Jewish masculinities, see also Breitman 1988; Kimmel 1988; Leifkovitz 1988.

53 Antonovsky 1956, 57; Berry 1990, 206. For example, when studying second-generation Jewish immigrant men in the USA, Antonovsky finds six different responses to a marginal situation: 1) active Jewish orientation; 2) passive Jewish orientation; 3) ambivalent orientation: marginal and conflicted; 4) dual orientation: integration into society; 5) passive general orientation: indifferent; and 6) active general orientation: assimilation without hiding or denying Jewishness. Antonovsky 1956, 60-61.

54 Berry 1990; 1997.

55 The most negative New Testament text toward Rome is the Book of Revelation, of course. On the opposite end is Luke, whose pro-Roman tendencies are well noted; see, e.g., Matthews 2010, 37-40. On the New Testament writers' different attitudes to Rome, ranging from positive to negative, see Carter 2006, 16-24.

$5^{6}$ Berry 1990, 216-217. 
with hegemonic masculinities. ${ }^{57}$ Another way to put this is to say that the marginality of early Christians may have been either voluntary or involuntary. I use the term "involuntary marginality" to refer to those who do not want to be marginal - that is, those that want to share the values and ideals of the hegemonic group and are "complicit" with it. Voluntary marginality, on the other hand, refers to those who accept and embrace their marginality. ${ }^{58}$ Furthermore, it is important to note that Berry's categorization is relatively simplistic. Instead of simple acceptance or resistance, it might be of value for a non-dominant group to have a relationship with the dominant culture in regard to some issues or to a certain extent. Acceptance and resistance form a continuum rather than a dichotomy. It is also possible that complicity and resistance are mixed together. Even though a marginal group may seem to be complicit with the hegemonic ideology, it might actually subvert it.

There could have been several early Christian masculinities, not just one. These early Christian masculinities could have had diverse strategies and ways of relating to the hegemonic masculinities of the ancient Greco-Roman world. In previous studies, it has been suggested that Luke had apologetic and proRoman tendencies, whereas Mark and Matthew shared more marginal ideals. ${ }^{59}$ Dennis Duling, for example, argues that Matthew advocates ideological marginality (that is, voluntarily accepting marginalization). ${ }^{60}$ Are these themes also evident in the Synoptic Gospels' portrayals of ideal masculinities? In this study, I examine how the Synoptic Gospels relate to the hegemonic masculinities of the ancient Greco-Roman world. How can the complex relationships between hegemonic and non-hegemonic masculinities be seen in the ancient Greco-Roman world? What kinds of relationships did the marginalized early

57 I propose that writings with an apologetic purpose are more likely to be complicit with hegemonic masculinities, since they intend to show that Christianity is not a threat to the dominant Roman order.

$5^{8}$ The terms "involuntary marginality" and "voluntary marginality" have also been used by Duling. For Duling, however, involuntary marginality is less about unwillingness and more about the inability to participate. Duling $(2002,521 ; 1993,645,648)$ maintains that involuntary marginality means that because of their sex, race, or ethnicity, people are "denied the opportunity to participate in roles expected of them." Voluntary marginality (Duling 2002, 521; 1993, 648), on the other hand, means that people consciously choose not to "live according to commonly accepted norms." Accordingly, in a later article, Duling (2002, 546-549) uses the term "structural marginality" instead of involuntary marginality and "ideological marginality" instead of voluntary marginality.

59 For Luke, see, e.g., Matthews 2010, 37-40; D’Angelo 2003b. For Mark and Matthew, see, e.g., Carter 1994; 2000; Barton 1994.

6o $\quad$ Duling 1993. 
Christian masculinities of the Synoptic Gospels have with the hegemonic masculinities of the wider Greco-Roman world?

\section{Outline of the Study}

Now it is time to go into more detail on the outline of the present study. Before moving on to study the Synoptic Gospels, we need to ascertain what the ideal hegemonic masculinities were like in the ancient Greco-Roman world. This enables comparison between the ancient Greco-Roman ideals and the ideals presented in the Synoptic Gospels. Chapter 2 examines masculinities in the Greco-Roman world and provides a background for the study of the ideal masculinities in the Synoptic Gospels. I employ a wide variety of sources in order to introduce the ideals of masculinity that existed in the ancient Greco-Roman world. As a result, it will be shown that there were several ideals of masculinity, even among the elite. Which one of these was the hegemonic masculinity? This problem can be solved by supposing that there were several ideal masculinities competing for the hegemonic position.

In the later chapters, the Synoptic Gospels are compared with these ideals. What are the ideal masculinities of the Synoptic Gospels? What kind of masculinity does their Jesus have? Which ideals do the Synoptic Gospels share with the masculinities that were competing for the hegemonic position and which are in opposition to hegemonic masculinities? Would ancient Greco-Roman readers have considered Jesus of the Synoptic Gospels to be masculine?

I organize my study around themes, instead of analyzing each Synoptic Gospel individually. This makes it easier to compare the Synoptic Gospels with each other. A possible limitation is that the overall picture of the ideal masculinity in each individual Gospel becomes more difficult to delineate. I attempt to correct for this downside in the Conclusions section of the chapter.

The themes that I concentrate on can be categorized into two groups: Jesus' relationships with other people and Jesus in relation to the ideal of self-control. Jesus' relationships with other people are studied in Chapters $3-5$. As noted above, gender is a relational concept. Masculinities are defined in relation to femininities and other masculinities. The men that Jesus interacts with form two groups. I investigate the first group of men, those who are antagonistic to Jesus, in Chapter 3 . The second group of men, those who are positive toward Jesus, is examined in Chapter 4. In Chapter 4, I also concentrate on Jesus' teaching on ideal discipleship. Marginal groups such as slaves, children, and eunuchs are also studied in this chapter. The women that Jesus meets do not form a homogenous group, but as there are fewer female characters in the 
Synoptic Gospels, the relationship between Jesus and women is studied only in one chapter, Chapter 5 . The next two chapters, Chapters 6 and 7 , concentrate on self-control in connection with emotions and suffering. Self-control, as we see in Chapter 2, was an important facet of masculinity in the Greco-Roman world. Nevertheless, different views on emotions and suffering are found in the ancient Greco-Roman texts. Chapter 6 concentrates on the Synoptic Gospels' portrayals of emotions, especially the emotions of Jesus. Chapter 7 examines Jesus' teaching on suffering, as well as the passion narratives. Finally, Chapter 8 summarizes the conclusions of this study. 